\title{
Saúde e Meio Ambiente: terapia e cuidado em tempos de coronavírus
}

\section{Health and Environment: therapy and care in times of Coronavirus times}

\section{Resumo}

O momento atual é preocupante e todo o planeta se volta para a saúde. Como combater a pandemia causada pelo vírus SARS-CoV-2? Há a preocupação com a descoberta imediata de vacinas que possam imunizar, proteger e salvar o ser humano. Mas e a indiferença em relação ao meio ambiente? Qual é a origem do descaso com a saúde do planeta terra? Vem de uma cultura religiosa, particularmente a judaico-cristã ou procede de um pensamento tecnocrático moderno cujo interesse se concentra no progresso e na riqueza dos homens? Na perspectiva do método ver, julgar e agir, muito utilizado em análises teológicas da doutrina social da igreja, este ensaio tem como objeto abordar a saúde como um problema a ser resolvido no âmbito holístico e na consciência do cuidado com a vida. O cidadão precisa se ver como terapeuta, capaz de cultivar o senso do necessário e aplicá-lo numa vida simples e saudável.

Palavras-chave: Saúde. Crise ambiental. Pandemia. Cuidado.

\section{Abstract}

The current moment is worrying and the entire planet is turning to health. How to fight the pandemic caused by the SARS-CoV-2 virus? There is 
concern about the immediate discovery of vaccines that can immunize, protect and save the human being. But what about indifference to the environment? What is the origin of the disregard for the health of planet Earth? Does it come from a religious culture, particularly Judeo-Christian, or does it come from a modern technocratic thought whose interest is concentrated in the progress and wealth of men? From the perspective of the see, judge and act method, widely used in theological analyzes of the church's social doctrine, this essay aims to approach health as a problem to be solved in a holistic context and in the awareness of caring for life. The citizen needs to see himself as a therapist, able to cultivate a sense of what is necessary and apply it in a simple and healthy life.

Keywords: Health. Environmental crisis. Pandemic. Care.

\section{Introdução}

Pensar a saúde ambiental em tempos de pandemia não é tarefa fácil no momento em que as preocupações imediatas, ao redor do mundo, se concentram na descoberta de antídotos que possam frear o contágio por SARS-CoV-2. Urge abordar as dificuldades que esta realidade impõe e os principais desafios que se colocam à ciência e à fé. José Roque Junges observa que a preocupação com a saúde humana deve considerar a degradação social e ambiental. Sendo assim, tratar a pandemia sem uma visão mais ampla da doença é circular pelos paliativos sem atingir a causa.

O Verdadeiro cuidado com os seres vivos é medido, em determinada sociedade, pelo modo como o ser humano é tratado. As chagas sociais da injustiça e da opressão são a primeira causa de um entorno degradado. Neste sentido não bastam soluções periféricas para a deterioração do meio ambiente, é necessária uma mudança radical no modo de estruturar a sociedade e organizar a economia. ${ }^{1}$

No momento atual, em que a ciência e a técnica investem em recursos para tornar a vida humana mais agradável, cabe perguntar: como está o meio ambiente e o espírito que move o ethos vivencial? Jean-Yves Leloup, ao definir

${ }^{1}$ JUNGES, J. R., Ecologia e Criação, p. 92. 
o cuidado como uma atitude responsável, retoma o termo grego terapeuen, utilizado na antiguidade para referir-se à cura em sua dimensão holística. Com a Modernidade, o termo foi utilizado no trato de doenças específicas, porém ao voltar ao pensamento clássico, sem ignorar as descobertas modernas, urge sugerir que o termo seja tomado de forma mais ampla, isto é, como ato de cuidar da vida preservando sua saúde, em todos os sentidos: físico, psíquico e espiritual.

À luz da fé cristã se pode compreender o autor bíblico ao abordar a criação como um ato de amor e cuidado: o Criador, no princípio, modelou o ser humano à sua imagem e semelhança, para executar o seu papel terapêutico em relação a todo ser criado (Gn 1-2). O papel do terapeuta é cuidar, preservar o que há de saudável e conduzir à cura o que está doente. O terapeuta está nesta vida "para pôr o doente nas melhores condições possíveis para que o Vivente atue e venha a cura". ${ }^{2}$

Diante do atual quadro pandêmico, referente à Covid-19 causada pelo vírus SARS-CoV-2, cabe a pergunta: a que se deve a preocupação em descobrir um antídoto que combata esta doença sem considerar o descaso em relação à saúde ambiental? Há os que responsabilizam a cultura judaico-cristã e os que atribuem às modernas tecnologias a causa do processo de degradação ambiental.

Para L. White Jr., é preciso considerar que o cristianismo, diferente do animismo que trata o ser humano como criatura, portanto parte da criação, vê no homem a "imagem e semelhança" de Deus criador formatando assim uma antropologia que, a partir de Gênesis (1,26-28), interpreta tal projeção como "Poder" do homem sobre toda a criação. Este tipo de visão daria origem a uma hermenêutica "que distancia o ser humano dos restantes seres naturais. Ele se sente sujeito diante de uma natureza objeto. Esse antropocentrismo abriu as portas para a exploração da natureza em proveito dos interesses humanos". ${ }^{3}$

Leonardo Boff, teólogo e ambientalista, por outro lado, observa que a crise ambiental ou ecológica é antropocêntrica, mas não crucifica a religião cristã. Para ele, a raiz do problema está na maneira como os seres humanos se relacionam com a terra. A crise ambiental é também ética. $O$ poder e a tecnologia são para a exploração, o lucro e a riqueza: "uma relação de domínio, de não reconhecimento de sua alteridade e de falta do cuidado necessário e do

\footnotetext{
${ }^{2}$ LELOUP, J. Y., Cuidar do Ser, p. 25-26.

${ }^{3}$ JUNGES, J. R., Ecologia e Criação, p. 14-15.
} 
respeito imprescindível que toda alteridade exige". ${ }^{4}$ Mircea Eliade, estudioso das religiões, fala de "dessacralização da natureza" e não concorda que a crise ambiental seja religiosa. Para ele, o mundo moderno padece de falta de religião:

O Cosmos se tornou opaco, inerte, mudo: não transmite nenhuma mensagem, não carrega nenhuma "cifra". O sentimento da santidade da Natureza sobrevive hoje na Europa sobretudo entre as populações rurais, pois é aí que ainda se encontra um cristianismo vivido como liturgia cósmica. $^{5}$

A causa da crise ecológica seria a cultura antropocêntrica judaicocristã ou as modernas tecnologias a serviço do lucro e da riqueza? Condenar a cultura judaico-cristã pela "dessacralização da natureza" é negar que, em geral, as grandes religiões são as que mantêm, neste mundo dominado pela ideia da exploração da natureza, uma relação sagrada com a criação. Eliade observa que não há como sustentar a fé na ideia materialista da "imagem e semelhança", como poder sobre a criação. Para se constituir como todo poderoso o indivíduo adota uma prática ateísta. $\mathrm{O}$ ateísmo prático torna $\mathrm{o}$ indivíduo desmistificado e livre de qualquer mandamento divino. $\mathrm{O}$ que liga o humano ao divino é a vida. Para Eliade, o que consagra a vida ou a torna sagrada é a perspectiva religiosa, como expressa citando o poeta, Leon Bloy: "Quer a vida esteja nos homens, nos animais ou nas plantas, é sempre a Vida, e quando vem o minuto, o ponto imperceptível que chamamos morte, é sempre Jesus que se retira, quer se trate de uma árvore ou de um ser humano". ${ }^{6}$ No que diz respeito à destruição, devastação ou morte violenta da natureza, verificadas especialmente na Modernidade, fica a questão: É justo responsabilizar a cultura judaico-cristã?

Os argumentos acima, apesar de opostos, ajudam a repensar a saúde do planeta e a procurar formas de cuidado que contemplem toda a criatura. A proposta deste ensaio, sob a orientação do método ver, julgar e agir, é abordar a saúde considerando-a numa perspectiva holística. Para tanto as duas concepções, tratadas acima, têm o seu lugar. No primeiro momento, tratarse-á da crise ambiental observando-a a partir do antropocentrismo moderno;

\footnotetext{
${ }^{4}$ BOFF, L., Ethos Mundial, p. 14.

${ }^{5}$ ELIADE, M., O Sagrado e o Profano, p. 145.

${ }^{6}$ ELIADE, M., O Sagrado e o Profano, p. 132.
} 
no segundo momento pensar-se-á a crise à luz de uma Teologia do cuidado e, por fim tratar-se-á de ações que podem minimizar impactos na natureza e na sociedade humana. Eis uma forma de abordar a saúde em seu aspecto mais amplo.

\section{Meio ambiente e crise ecológica}

O Neoliberalismo, na esteira do capitalismo moderno, sustenta uma narrativa que coloca o "saudável" ligado ao bem-estar econômico. A saúde, que deveria ser concebida em sua forma mais ampla, passa a ser secundária. Assim, perde-se saúde para ganhar dinheiro para depois perder dinheiro para recuperar a saúde. Quais são as prioridades da vida? O ter suplanta o ser e, não raras vezes, a pessoa só se dá conta disso quando fica doente ou é ameaçada pela morte. Diante da exploração predatória e desmedida, incentivada pelo progresso da ciência e da tecnologia, ligado ao capital, é preciso pensar a saúde em sua forma mais ampla, considerando sobremaneira o meio ambiente. A degradação da natureza é um problema colocado à saúde de todos os seres.

As raízes da crise ecológica, na visão de Gadamer, estão ligadas ao progresso da ciência moderna: "Infelizmente, temos de admitir para nós mesmos que o que se seguiu ao progresso da ciência foi o enorme retrocesso no cuidado geral com a saúde e na prevenção de doenças". ${ }^{7}$ Nesta direção, porém criticando o viés unilateral do paradigma tecnocrático, segue o Papa Francisco. Em sua epistola Laudato Sì observa que a terra está doente e pede socorro. ${ }^{8}$ É tarefa de todos preocuparem-se com a saúde do planeta e reagir à aliança tecnocrática da modernidade. Entende-se por modernidade o período da história em que a razão humana, em sua tendência cientificista, se acha capaz de construir ao ser humano um paraíso de prosperidade já nesta terra. ${ }^{9}$ Segundo o Pontífice, é preciso reagir a esta visão materialista da "prosperidade" sem "frustrar a expectativa divina". Esta reação deve ser global e atingir, além das ações locais, as cúpulas mundiais. É preciso "reconhecer que sempre há uma saída, sempre podemos mudar de rumo, sempre podemos fazer alguma coisa para resolver os problemas". ${ }^{10}$ A crise ecológica, relacionada à globalização tecnocrática, se mostra na poluição do ar, da água, nas mudanças climáticas, na

\footnotetext{
${ }^{7}$ GADAMER, H. G., O Caráter oculto da saúde, p. 111.

${ }^{8}$ LS 6.

${ }^{9}$ SOUZA, J. N., Imagem humana à Semelhança de Deus, p. 142.

${ }^{10}$ LS 61.
} 
perda da biodiversidade tendo como consequência novas doenças e pandemias e na degradação da vida humana.

A poluição do ar, a queima de combustíveis fósseis e o desmatamento e outras ações humanas, são os grandes vilões desta crise, ao mesmo tempo em que aumentam assustadoramente a quantidade de gases na biosfera, impedem que uma boa parte dos raios volte para o espaço, elevando assim a temperatura do planeta. $\mathrm{O}$ efeito desta degradação ambiental já se faz sentir. No relatório da $\mathrm{ONU}$, atualmente já há uma grande escassez de água. ${ }^{11}$ Até 2025 provavelmente 4 bilhões de pessoas sofrerão por falta de água potável, sem contar a perda da biodiversidade e da população de animais que correm o risco de extinção, como bem expressa Francisco:

As estradas, os novos cultivos, as reservas, as barragens e outras construções vão tomando posse dos habitats e, por vezes, fragmentam-nos de tal maneira que as populações de animais já não podem migrar nem se mover livremente, pelo que algumas espécies correm o risco de extinção. ${ }^{12}$

A degradação ambiental redunda em degradação social e humana. São poucos os que lucram com a pobreza de muitos fazendo recair sobre os mais frágeis uma péssima qualidade de vida. E isso não só em nível nacional, mas planetário.

Constata-se, ao analisar o pensamento moderno, que a indagação sobre o universal, a totalidade, enquanto interligação das partes, deixou de ter a atenção à medida que se reduziu ou limitou a relação com a transcendência ou o sagrado. O que era do nível do equilíbrio, da preservação da natureza como espaço espiritual, deu lugar à exploração predatória, ao consumo e ao descarte; uma economia do fetiche, do mercado e da moeda. Nesta nova compreensão, religião só tem sentido se serve aos interesses de um, de poucos ou de uma massa. Todos em busca do imediato. A vida se limita ao aqui e agora. A perda da dimensão universal da natureza afastou o ser humano da essência, de sua preocupação com o equilíbrio e com a totalidade das coisas. Eliade concorda que a perda do universal é também perda do simbólico. A natureza deixou de ser encantada:

${ }^{11}$ CNUMAD (Conferência das Nações Unidas Sobre Meio Ambiente e Desenvolvimento), Agenda 21.

${ }^{12}$ LS 35. 
O símbolo não somente torna o Mundo "aberto", mas também ajuda o homem religioso a alcançar o universal. Pois é graças aos símbolos que o homem sai de sua situação particular e se "abre" para o geral e o universal. Os símbolos despertam a experiência individual e transmudam-na em ato espiritual, em compreensão metafísica do mundo. Diante de uma árvore qualquer, símbolo da Árvore do Mundo e imagem da Vida cósmica, um homem das sociedades pré-modernas é capaz de alcançar a mais alta espiritualidade: ao compreender o símbolo, ele consegue viver o universal. ${ }^{13}$

A perda da dimensão simbólica e holística leva à incapacidade de distinguir o saudável do não-saudável. É preciso resgatar o conceito de saúde como interligação. A esta fragmentação da natureza, submetida a um "reducionismo científico-metodológico", urge conceber uma "cultura sistêmica que compreende as inter-relações presentes no ambiente". ${ }^{14}$

A saúde, reduzida ao bem-estar físico, está relacionada à fragmentação social e ambiental. A população de um país, rico em bens naturais, devido à injusta distribuição dos recursos fundamentais à sobrevivência e à acumulação de poucos, pode ser excluída de um ambiente de boa qualidade de vida.

Ao confrontar os conceitos de saúde e crise ambiental, numa perspectiva moderna, é importante uma análise mais profunda destes conceitos entendidos como interligados. Nesse sentido, é justo tratar de "Saúde integral", isto é, o equilíbrio ou unicidade na relação físico-psíquico-espiritual. Jean-Yves Leloup, à luz dos terapeutas do deserto, observa que tal harmonia é análoga àquela que vemos "entre o fundo e a forma, entre a palavra e o pensamento, entre a palavra e a vida". ${ }^{15}$

\section{Saúde: a perspectiva do necessário}

As partes interligadas falam do todo. Quando se trata da saúde física, psíquica e espiritual, necessariamente parte-se de uma antropologia que transcende o real e considera sua totalidade em sua dimensão simbólica. Aristóteles via que tudo está interligado, porém diferenciava conceitualmente o necessário do acidente; universal do particular. Sua Lógica ensina a perguntar

\footnotetext{
${ }^{13}$ ELIADE, M., O Sagrado e o profano, p. 172.

${ }^{14}$ JUNGES, J. R., Ética Ambiental, p. 51.

${ }^{15}$ LELOUP, J. Y., Cuidar do Ser, p. 79.
} 
ao sujeito acerca da necessidade do Predicado. ${ }^{16}$ Se o atributo do predicado for indispensável ao sujeito, então tal atributo é essencial ou universal, sem o qual ele não pode existir. Já o atributo dispensável ao Sujeito é algo particular ou acidental, sem o qual o sujeito continua sendo. Eis a proposição: "o homem é mortal”. Pergunta-se ao sujeito: é necessário ser mortal para ser homem? A resposta é sim, então a partícula "o" indica a extensão universal do sujeito, isto é "todo". O atributo de mortalidade é essencial, universal e necessário ao ser humano para que ele se constitua como tal. Já na proposição: "o homem é carnívoro", a partícula "o" indica que o sujeito é particular, pois não é necessário ser carnívoro para ser homem, comer carne não constitui a essência humana; é algo dispensável e acidental, é uma questão de hábito e não de vida saudável.

Derrubar florestas e vegetações, necessárias à saúde humana e animal, a fim de cultivar animais para alimentar a humanidade é algo contingente, nãoessencial. Não necessariamente comer carne é sinônimo de saúde. A mesma lógica se aplica às experiências científicas com animais. A saúde humana não depende destes testes, há outras vias de pesquisas e mais saudáveis. Não é necessária a morte de animais para a sobrevivência humana. A saúde é essencial à pessoa, sacrificar animais não; o ar é necessário, o desmatamento e a emissão de gás poluente na atmosfera não são.

É nesta perspectiva que o conceito de saúde precisa ser retomado. Tudo está interligado. Não se contentar com o conceito moderno que liga saúde a bem-estar econômico é o primeiro passo para uma consciência crítica de perspectiva holística, necessária e vital a todo ser. A saúde, numa concepção fragmentada, própria da modernidade tecnocrata, não pode ser entendida como doença? O cuidado com a vida, numa visão universal, considera a saúde como equilíbrio do todo, sem fechar os olhos às situações provocadoras de violência e injustiça aos mais fragilizados.

O termo "saúde", no grego antigo, aponta para a ideia do termo о $\lambda$ ок $\lambda \eta \rho \iota \alpha$ que significa "perfeito" ou "inteiro". Saúde, sob o verbo $\sigma o \zeta \omega$ (sõzõ), indica "salvar". A salvação é holística, é completude e inteireza, como bem observou Gadamer: "O ser integral do todo e o ser sadio da pessoa sã, a sua saúde, parecem estar estreitamente ligados. Quando estamos doentes, também dizemos que algo nos falta". ${ }^{17}$ Cadeia de relações, o ser humano é o único mamífero capaz de ver um mundo a ser construído. Berger observara

\footnotetext{
${ }^{16}$ Sobre a Lógica de Aristóteles ver: KELLER, V.; BASTOS, C. L., Aprendendo Lógica, p. 49-108.

${ }^{17}$ GADAMER, H. G., O Caráter Oculto da Saúde, p. 80.
} 
que, longe de ser um fenômeno estranho, o "por fazer" que se coloca diante da pessoa constitui a sua essência biológica. ${ }^{18}$ Nesse sentido, é uma ação que aponta para o simbólico, a transcendência de si mesmo em busca de preservação e prevenção a vida. Para Hans Jonas, a tendência para salvação universal já prefigurava no homem primitivo e hoje continua como parte orgânica da sua existência. ${ }^{19}$

O corpo, considerando esses autores, mais que um organismo biopsíquico-espiritual é ser interligado socialmente e ecologicamente. Tudo o que se relaciona à saúde pode ser tomado numa perspectiva da transcendência e tratado de forma holística e integral.

No encontro com o pensamento grego, o Cristianismo aprendeu o valor da unidade na pluralidade e vice-versa. O todo contém as partes e, sem elas, ele não tem razão de ser. Na unidade das partes habita a sua essência. Ignorar a totalidade em favor dos fragmentos, o universal em prol do particular e valorizar os membros em detrimento do corpo significa reduzir o ser a indivíduo. Esta ideia cultiva um "si mesmo" alienado aos próprios interesses. Sem a perspectiva da totalidade a transcendência fica comprometida e o equilíbrio corroído.

O conceito de equilíbrio, trabalhado no pensamento grego e assimilado na prática médica, expandia o conceito de saúde. É na relação ser humano e natureza que se deve buscar a transcendência. Bem observou Gadamer:

Natureza é, portanto, como algo que mantém a si mesmo e se mantém por si mesmo nas suas trajetórias. Esse é o pensamento básico da cosmologia jônica, no qual todas as representações cosmológicas cumprem a sua função de que, no final, a grande ordem equilibradora do acontecimento alternante determina tudo como uma justiça natural. ${ }^{20}$

À idéia de saúde integral, natureza, transcendência e equilíbrio, pode se juntar o conceito de "biosfera", assimilado e desenvolvido pelo pensador russo Wladimir Vernadsky (1863-1945). A esfera da vida diz respeito a todo ser vivente. A pluralidade de seres deve ser concebida como totalidade. "Tudo está interligado". O papel do terapeuta deve se voltar para a realidade da vida e perguntar sobre o que é ter saúde.

\footnotetext{
${ }^{18}$ BERGER, P., O Dossel Sagrado, p. 18.

${ }^{19}$ JONAS, H., O Princípio Vida, p. 11.

${ }^{20}$ GADAMER, H. G., O Caráter Oculto da Saúde, p. 44.
} 


\section{Exigências terapêuticas em tempos de Coronavírus}

Em situação de desequilíbrio físico, psíquico e social, o cuidado com a vida precisa ser redobrado: cuidado com os mais vulneráveis da sociedade; cuidado com a terra que grita em favor das plantas, do ar, das águas, dos animais etc. Na situação atual, em que a preocupação se centra na pandemia de Covid-19, urge dirigir sua atenção para a saúde planetária e rever os hábitos ligados à forma de exploração predatória que se instaurou após a revolução industrial e que avança exponencialmente.

Alguns economistas comprovaram que menos de 1\% do PIB mundial poderia reduzir $35 \%$ das emissões de carbono na atmosfera. Para isso devia haver um compromisso com a saúde mundial e os países desenvolvidos seriam os primeiros a tomarem as providências necessárias como investimento em tecnologias sustentáveis e limpas, políticas de reciclagem de lixo sem enviálos a países pobres como lugar de descarte e descobrirem novas fontes de energia não poluidoras. São necessárias atitudes sábias a fim de tornar o mundo mais saudável. Produzir riquezas não precisa ser sinônimo de destruição do meio ambiente. Sabedoria é produzir conhecimentos que conciliem desenvolvimento e preservação dos recursos naturais.

A solução não é voltar ao normal, o que parecia ser o melhor antes da pandemia do coronavírus, mas transformar a mentalidade. Na falta de uma fórmula pronta, há que se concordar com algumas iniciativas práticas cuja concepção de saúde aponta para o todo, para o planetário: a primeira, encabeçada pelo teólogo Leonardo Boff, que ligando espiritualidade, saúde e teia da vida propõe alguns pactos de cuidado humano com a natureza. A segunda vem do ambientalista Gregorio Iriarte que propõe seis alternativas reais e viáveis em favor do "compromisso mundial". ${ }^{21}$ A terceira vem do Instituto Akatu cuja missão, segundo André Trigueiro, é formar o "Consumidor consciente" a partir de ações responsáveis. ${ }^{22}$

Para Boff, os pactos de responsabilidade com o meio ambiente são: 1) Responsabilidade pelo meio ambiente; 2) Responsabilidade pela qualidade de vida de todos os seres e 3) Responsabilidade generacional: são compromissos práticos que transcendem a vida presente e são essenciais para gerações futuras. ${ }^{23}$ Para que isso aconteça, é fundamental o retorno de um pensamento

${ }^{21}$ IRIARTE, G., A globalização neoliberal, p. 21-39.

22 TRIGUEIRO, A., Mundo Sustentável, p. 21-32.

${ }^{23}$ BOFF, L., Ethos Mundial, p. 92. 
que considera o ser humano como ser finito, hóspede da terra, capaz de sair do imediatismo e da cegueira em relação ao futuro.

Para Iriarte, é preciso fazer mudanças. ${ }^{24}$ Propõe: 1) uma "terceira via". Que esta mudança parta de todos, ricos e pobres conscientes e indignados com o capitalismo selvagem que vigora; 2) um modelo pós-capitalista voltado para o bem-estar, qualidade de vida e a construção de um "outro mundo possível", debatido com frequência nos "fóruns sociais",25 3) consciência do "bem comum" onde o "eu" só tem razão de existir em relação ao "nós"; 4) O Estado, consciente de seu papel, fiscaliza e corrige o jogo e a "selvageria" do lucro; 5) vida ética que tem como princípios superar a desigualdade econômica e a injustiça social globalizadas, que tais princípios se baseiam na necessidade política de solidariedade, participação, direito, igualdade e justiça social; 6) O desenvolvimento humano é o fundamento de toda política, por isso deve se basear na qualidade de vida, sustentação e defesa do meio ambiente.

Por fim, a terceira saída, a do "consumidor consciente" (Akatu), propõe viver segundo os quatro R. Pode não ser muito, mas já é um passo em direção à preservação da saúde ambiental. ${ }^{26} 1$ ) Repensar: é preciso que cada um reflita sobre a realidade e seus atos de consumidor para que possa criar uma consciência universal de responsabilidade em relação à saúde planetária. Seu objetivo é criar uma ética capaz de transformar o mundo a partir do conceito de necessidade. Formar a consciência crítica é fundamental no processo de construção de um mundo sustentável. 2) Reduzir: Consumir o necessário e evitar a produção de lixo, principalmente as embalagens plásticas e produtos descartáveis. 3) Reutilizar: A vida útil dos produtos depende de nós. Aumentála a fim de não gerar lixo, já é uma diminuição de resíduos, importante para a "nossa casa comum" (Papa Francisco). Produtos de maior durabilidade podem ajudar a diminuir o desperdício de recursos; 4) Reciclar: Colaborar com as iniciativas e cooperativas que reciclam, não misturar objetos como papéis limpos, vidros, plásticos e metais com o lixo comum. Incentivar a coleta seletiva e as cooperativas de catadores já ajuda a minimizar os impactos na natureza.

\footnotetext{
${ }^{24}$ IRIARTE, G., A Globalização neoliberal, p. 32-35.

${ }^{25} \mathrm{O}$ Fórum social regional e mundial é uma atuação política, não profissional, mas participativa. Há dois tipos de Fórum: um ligado ao poder internacional, o outro, livre, proposto pelos participantes, com discussões em oficinas e seminários em busca de alternativas viáveis para a vida.

${ }^{26}$ TRIGUEIRO, A., Mundo Sustentável, p. 21-32.
} 
A pessoa, consciente do que é essencial à sua existência pode, com responsabilidade, achar uma saída sustentável. É fundamental a "diminuição" da poluição, do reaproveitamento do lixo e de uma nova noção de "necessidade", já que evitar o consumo é uma tarefa quase impossível. São alternativas importantes e podem ser reduzidas a duas: cultivar, no cuidado, o senso do necessário e viver de maneira mais simples e saudável. $\mathrm{O}$ cuidado com a criação e a preocupação com a saúde são essenciais na relação ser humano e meio ambiente. Gadamer observa que o ser humano pode exercer o seu papel de terapeuta, constituição básica no seu "por fazer". Seu papel diz respeito "não apenas a recuperação do doente, mas, com recolocação, a restituição e o retorno ao seu ser-capaz-defazer e ao seu ser, devolver-lhe a unidade consigo mesmo". ${ }^{27}$

\section{Conclusão}

Todas as pessoas, animais e vegetais têm o direito à saúde, água boa, ar puro, terra fértil e alimentação saudável. A destruição das florestas, a poluição do ar e das águas, o abate, o tráfico e a experimentação de animais apontam para um desequilíbrio da natureza. A saúde humana depende da saúde ambiental planetária e vice-versa. A solução para a fome no mundo não está em devastar florestas e cultivar animais, mas na partilha e na distribuição justa da renda.

Refletir sobre saúde e meio ambiente e sentir a necessidade de mudar a mentalidade em relação ao futuro do planeta, eis o objetivo deste ensaio. É preciso buscar meios sustentáveis para a qualidade de vida dos seres vivos sem que, para isso, tenha que causar impactos drásticos ao ecossistema. A saúde integral considera o ser em sua integridade, por isso, também no que diz respeito a uma espiritualidade sadia, só na alteridade se pode considerar o semelhante e a natureza que o cerca, não só como matéria, mas fonte do sagrado: o fascinante, o intocável e o puro. Em nome de uma concepção de saúde que leve a uma vida abundante, é preciso outro olhar que não seja o da exploração desenfreada da natureza. Outro mundo possível que, diante da natureza, faz nascer:

O desejo maternal de acolhê-la, de estabelecer novas relações e esconjurar a manipulação expoliadora e instrumentalista. A natureza nos faz sonhar outra vida, outro estilo de vida e de ser humano; desperta a utopia messiânica que mostra a criança brincando tranquilamente com a serpente: convida-nos a imaginar um mundo onde os foguetes espaciais não levem

${ }^{27}$ GADAMER, H. G., O Caráter Oculto da Saúde, p. 93. 
dez ogivas nucleares e se convertam em arados que proporcionem água, pão e vida ao Terceiro Mundo e a todos os seres humanos. A preocupação com a natureza nos devolve à nossa condição de administradores cautelosos, irmãos e filhos da Mãe primigênia. Uma relação, dependência que se faz veneração, se desata ao olhar "Gaia", a Mãe terra. ${ }^{28}$

Preocupar-se com a natureza já é sinal de novos tempos, pois é incluí-la sob a ótica da unidade, do todo. Para que uma religião não seja julgada como causa de destruição do meio ambiente e responsabilizada pelos graves problemas de saúde pelos quais passam a humanidade, ela deve ser terapêutica, cultivar o simbólico que aponta para a saúde planetária; deve incluir em seus dogmas o respeito e o cuidado, não só para com o ser humano, mas com a natureza e seus habitantes; deve denunciar uma monocultura que utilize agrotóxicos e produza transgênicos sem pensar nas consequências nefastas à vida; deve questionar a justificativa do capital que, em nome da "alimentação da população mundial", investem em desmatamentos e interferem na qualidade de vida das pessoas e do meio ambiente. Uma frase atribuída a Confúcio diz: "os homens ainda vivem, como se nunca fossem morrer e morrem como se nunca tivessem vivido".

É fundamental repensar a saúde a partir da crise ambiental que se estabeleceu pós-revolução industrial e discuti-la no Congresso Nacional, nas escolas e universidades. É uma realidade a ser monitorada de tal forma a buscar o equilíbrio, há muito perdido, como bem observa Natal: "Urge priorizar sistemas com metas auto-sustentáveis e menos agressivos, onde os princípios ecológicos sejam otimizados e não contrariados" ${ }^{29}$ Cuidar do ser em todas as suas dimensões, pode até não erradicar o coronavírus, mas contribuirá para minimizar os impactos que esta pandemia vem causando à saúde humana e à vida na terra.

\section{Referências bibliográficas}

BERGER, P. O Dossel Sagrado. São Paulo: Paulinas, 1985.

BOFF, L. Ethos mundial: Um consenso mínimo entre os humanos. Rio de janeiro: Sextante, 2003.

CNUMAD (Conferência da Organização das Nações Unidas Sobre Meio

${ }^{28}$ MARDONES, J. M., A Vida do Símbolo, p. 195-196.

${ }^{29}$ NATAL, D.; MENEZES, R. M. T.; MUCCI, J. L. N., Fundamentos da Ecologia, p. 83. Este texto foi produzido antes do novo acordo ortográfico. 
Ambiente e Desenvolvimento). Agenda 21. São Paulo: Secretaria de Estado do Meio Ambiente, 1997.

ELIADE, M. O Sagrado e o profano. São Paulo: Martins Fontes, 2001.

FRANCISCO, PP. Carta Encíclica Laudato Si': sobre o cuidado da casa comum. São Paulo: Paulinas, 2015.

GADAMER, H. G. O Caráter oculto da saúde. Petrópolis: Vozes, 2006

IRIARTE, G. "A globalização neoliberal: absolutização do mercado que a tudo coloniza”. In: SOTER; AMERÍNDIA (Orgs.). Caminhos da Igreja na América Latina e no Caribe. São Paulo: Paulinas, 2006, p. 21-39.

JONAS, H. O Princípio Vida. Petrópolis: Vozes, 2004.

JUNGES, J. R. Ecologia e Criação. São Paulo: Loyola, 2001.

JUNGES, J. R. Ética Ambiental. Porto Alegre: Unisinos, 2004.

KELLER, V.; BASTOS, C. L. Aprendendo Lógica. Petrópolis: Vozes, 2001. LELOUP, J. Y. Cuidar do Ser. Petrópolis: Vozes, 1996.

MARDONES, J. M. A Vida do símbolo. São Paulo: Paulinas, 2006.

NATAL, D.; MENEZES, R. M. T.; MUCCI, J. L. N. Fundamentos de Ecologia humana. In: PHILIPPI Jr., A. Saneamento, Saúde e Ambiente. Barueri, SP: Manole, 2005. p. 57-86.

SOUZA, J. N. Imagem humana à Semelhança de Deus: Proposta de Antropologia Teológica. São Paulo: Paulinas, 2010.

TRIGUEIRO, A. Mundo Sustentável. São Paulo: Editora Globo, 2005.

José Neivaldo de Souza

Doutor em Teologia Fundamental pela Pontificia Università Gregoriana Curitiba / PR - Brasil E-mail: neivaldo.js@gmail.com

Recebido em: 03/03/21

Aprovado em: 14/06/21 